\title{
Patient and injury characteristics associated with road traffic mortality in general hospitals in southern Thailand
}

\author{
Sunee Kraonual ${ }^{1,2}$, Apiradee Lim ${ }^{1,2 ; *}$, Attachai Ueranantasun', Sampurna Kakchapati ${ }^{1,3}$
}

Abstract

Background: Road traffic injuries are a major public health burden in developing countries. Thailand has the highest fatality rate from road traffic injuries in southeast Asia so that prevention of unintentional injuries is important.

Objective: To identify patient and injury characteristics associated with road traffic mortality in the southern provinces of Thailand.

Methods: Data on a total of 78,862 road traffic injuries recorded by the general hospitals in 5 southern provinces of Thailand, during 2008-2013, were obtained from the Office of Disease Prevention and Control. Chi-squared test was used to determine the association between patient/injury characteristics and road traffic mortality, and logistic regression was used to identify the strength of associations.

Results: In this study, road traffic mortality was found to be $1.8 \%$ of all injuries. Most of the deaths occurred in males (61.7\%), who were aged 25-44 years (35.8\%), being drivers (68.6\%), using motorcycle (78.4\%), and not wearing a helmet $(61.0 \%)$. Road traffic mortality was higher among males, older age people, those who were not wearing a helmet or not fastening a seat belt, pedestrians and when people crashed with or by motor car, with wound being penetrating or blunt with penetrating, and when they were having head or neck, chest, or abdominal or pelvic cavity injuries.

Conclusion: Policies and measures for reducing road traffic mortality should focus on males and older aged persons, use of safety devices, and occurrence of multiple injuries.

Keywords: accidents; traffic; mortality; wounds and injuries

More than 1.25 million road traffic injuries occur globally each year with huge impacts on health and development of countries, but they could be partly preventable [1]. Approximately $50 \%$ of the world's injury-related morbidity and mortality occur in teenagers and young adults aged between 15 and 44 years [2-4]. The low- and middle-income countries are the hardest hit, with double the fatality rates of high-income countries and accounting for $90 \%$ of global road traffic deaths [1].

High traffic mortality rate is common in the southeast Asian countries. Annually, it is estimated that there are approximately 316,000 traffic death cases in southeast Asia, accounting for $25 \%$ of the global deaths from traffic accidents [5].

*Correspondence to: Apiradee Lim, Department of Mathematics and Computer Science, Faculty of Science and Technology, Prince of Songkla University, Pattani 94000, Thailand. e-mail: apiradee.s@psu.ac.th

'Department of Mathematics and Computer Science, Faculty of Science and Technology, Prince of Songkla University, Pattani, Campus, Muang, Pattani 94000, Thailand

${ }^{2}$ Centre of Excellence in Mathematics, Faculty of Science, Mahidol University, Bangkok 10400, Thailand

${ }^{3}$ Advance Public Health Faculty, Nobel College, Kathmandu 44600, Nepal

¿ Open Access. @ 2019 Sunee Kraonual et al., published by Sciendo. (cc) BY-Nc-ND This work is licensed under the Creative Commons Attribution NonCommercial-NoDerivatives 4.0 License. 
In southeast Asia, Thailand had the highest rate, 36.2 per 100,000 population fatality rate from road traffic injuries in 2013 , while the average rate was 17.0 per 100,000 population in this region [5].

Several factors are associated with traffic mortality, including demographic factors and injury characteristics [6-9]. The traffic injury mortalities occur among males by two-thirds more than among females, for cases aged under 40 years and being motorcyclists $[10,11]$. In low-income countries, $45 \%$ of the traffic mortalities are pedestrians, whereas the corresponding figure is $29 \%$ in middle-income and $18 \%$ in high-income countries [12]. Mostly, the mechanism of injuries is blunt [13]. Moreover, mortality from traffic accidents is higher during holidays, for example, during New Year or Thai New Year holidays (locally known as Songkran holidays) [7]

The proper use of a motorcycle helmet can reduce the risk of death by almost $40 \%$ and the risk of severe injury by over $70 \%$ [1]. Several studies had also shown that the epidemiological characteristics and injury profiles are related to road traffic mortality $[8,14-16]$. Head or body injuries are the most common cause of traffic accident-induced mortality worldwide [17-21].

The road traffic injuries remain a major public health problem in Thailand. However, there was no national system for collecting traffic injury data before 1990, so that information for setting up the proper policies to prevent and solve injury problems was lacking. Therefore, the Epidemiology Division of the Thai Ministry of Public Health designed an injury surveillance (IS) system in 1992 to set up a proper data collection system. After that, all the injury cases seeking care at an emergency department (ED) were recorded, and the data are collected from 5 sentinel hospitals in 4 regions and in Bangkok, starting from 1995. This was expanded gradually and voluntarily to 22 hospitals in 2001 and became the National Injury Surveillance System (NISS), which includes only severe injury cases, and expanded to 29 sentinel hospitals in 2004 [22]. A large injury data have been produced. A cohort study on predictors of injury mortality in Thailand focusing on non-transport injuries reported that southern residents had higher injury mortality compared to other regions [23]. This study aimed to identify patient demographic factors and characteristics of injuries associated with road traffic mortality. Results from this study can be used as baseline data for policy makers and other stakeholders on the management and prevention of mortality from traffic injuries in the hospital.

\section{Methods}

Data on traffic injuries were obtained from IS database between 2008 and 2013, from the Office of Disease Prevention and Control (ODPC). These data are hospital-based data collected from general hospitals of 5 provinces in upper southern Thailand. Data were collected by using an IS form. Patient and injury characteristics were obtained by interviewing patients or bystanders, performed by nurses. Information on demographic factors of patients including age and gender, and injury characteristics including road user type, type of vehicle, safety device use, pattern of crash, mechanism of injury, body region of injury, and survival status after receiving treatment were extracted from the database. Patients could have died at any stages before, during or after treatment in the ED or the inpatient department (IPD). There were 78,862 cases of traffic injuries included in this study. Data were cleaned to eliminate the errors of coding and recording before performing data analyses. Age group was classified as below 15, 15-24, 25-44, and 45 years and older. Road user type was grouped as drivers, passengers, pedestrians, and unknown. Type of vehicle was categorized as motorcycle, motor car, pedestrian, others, and unknown. Fastening seat belt or helmet was grouped as yes, no, and unknown. Pattern of road traffic crash was categorized as crashed with or by a motorcycle, crashed with or by motor car, crashed with or by others, and unknown. Mechanism of injuries was grouped as blunt, penetrating, or blunt with penetrating, and unknown. Body region of injuries was categorized as head or neck, facial, chest, abdominal or pelvic cavity, extremities or pelvic girdles, external injuries, and unknown.

Descriptive statistics were calculated for each variable. In this study, the determinants consist of patient demographic factors and injury characteristics. The outcome is road traffic mortality. Chi-squared test was used to find the association between determinants and outcome. Logistic regression analysis was performed to identify the strength of association between determinants and outcome. $P$-value of $<0.05$ was used to define statistical significance. Adjusted odds ratios (aORs) together with their $95 \%$ confidence intervals (95\% CIs) were used to describe the independent association between predictors and outcome. R program was used for data management and statistical analysis [24].

\section{Results}

Road traffic injuries were equally distributed by year, except for the year 2008 with the lowest percentage (9.1\%). The majority of injuries occurred in males $(61.7 \%)$. Patients aged 25-44 years had the highest percentage of road traffic injuries (35.8\%) followed by age groups 15-24 years (30.2\%), and 45 years or older $(19.2 \%)$, respectively. The majority of road user types were drivers (68.6\%) and motorcyclists (78.4\%). There were $61.0 \%$ of injury cases who did not wear a helmet. The major pattern of road traffic crash was crashing with or by 
motor car, accounting for $24.2 \%$, followed by crashed with or by motorcycle for $21.7 \%$. The typical mechanism of injuries was blunt, accounting for $88.8 \%$. About $45.7 \%$ of injuries by body region were external injuries. There were $1.8 \%$ of patients who died from traffic injuries as summarized in Table 1.

Table 2 summarizes the associations between road traffic mortality and independent variables based on chi-squared test. To eliminate the collinearity between the variables, type of road users, type of vehicle, and safety device use were combined to create a new variable called road user-vehicle type-safety device use. The results showed that three-fourths of road traffic deaths occurred in males (75.3\%). The predominance of deaths occurred in the age group from 25 to 44 years, accounting for $44 \%$. About $37.6 \%$ of deaths were drivers or passengers using motorcycle and not wearing helmet, whereas $9.9 \%$ of deaths were drivers or passengers using motor car and not fastening the seat belt. Most of the deaths were by crash by motor car, accounting for $42.4 \%$. The major mechanism of injury among the death cases was blunt $(82.2 \%)$. There were $45.8 \%$ of deaths from head or neck injuries. Results from chisquared test show that gender, age group, road user-vehicle type-safety device use, pattern of traffic crash, mechanism of

Table 1. The distribution of demographic factors and injury characteristics in relation to road traffic mortality

\begin{tabular}{lcc}
\hline Patient and injury characteristics & $\begin{array}{c}\text { Number } \\
(\mathbf{N}=\mathbf{7 8 , 8 6 2})\end{array}$ & Percent (\%) \\
\hline Year of injuries & & \\
2008 & 7,184 & 9.1 \\
2009 & 14,962 & 19.0 \\
2010 & 14,504 & 18.4 \\
2011 & 14,486 & 18.3 \\
2012 & 13,863 & 17.6 \\
2013 & 13,863 & 17.6 \\
Gender & & \\
Male & 48,691 & 61.7 \\
Female & 30,171 & 38.3 \\
Age groups & & \\
<15 years & 11,695 & 14.8 \\
15-24 years & 23,824 & 30.2 \\
25-44 years & 28,208 & 35.8 \\
य45 & 15,135 & 19.2 \\
Type of road users & & \\
Driver & 54,121 & 68.6 \\
Passenger & 19,302 & 24.5 \\
Pedestrian & 2,777 & 3.5 \\
Unknown & 2,662 & 3.4 \\
Type of vehicles & & \\
Motorcycle & 61,832 & 78.4 \\
Motor car & 7,746 & 9.8 \\
Pedestrian & 2,777 & 3.5 \\
Other & 3,935 & 5.0 \\
Unknown & 2,572 & 3.3 \\
\hline & & \\
\hline
\end{tabular}

injuries, and body region of injuries were significantly associated with road traffic mortality $(P<0.001)$ as summarized in Table 2.

Table 3 summarizes the association between demographic factors and injury characteristics with road traffic mortality from multivariate analysis. The results showed that gender, age group, road user-vehicle type-safety device use, pattern of road traffic crash, mechanism of injuries, and body region of injuries were statistically significantly associated with road traffic mortality. Males were more likely to die from road traffic injury than females by 1.66 times. Road traffic mortality significantly increased with age. Patients aged 15-24, $25-44$, and 45 years and older were more likely to die by 1.95 , 2.83 , and 2.82 times than patients aged less than 15 years. Driver or passenger using motorcycle and not wearing helmet, driver or passenger using motor car not fastening seat belt and pedestrian had higher morality than driver or passenger using motorcycle and wearing a helmet by $2.08,3.37$, and 5.65 times, respectively. Those with penetrating or blunt and penetrating injuries were more likely to die by 1.55 times than those with only blunt injuries. Those who crashed or were crashed by motor car had higher mortality than those who crashed or

\begin{tabular}{|c|c|c|}
\hline Patient and injury characteristics & $\begin{array}{c}\text { Number } \\
(\mathrm{N}=\mathbf{7 8 , 8 6 2})\end{array}$ & Percent (\%) \\
\hline \multicolumn{3}{|l|}{ Used a helmet or fastened seat belt } \\
\hline Not wearing a helmet & 48,063 & 61.0 \\
\hline Wearing a helmet & 10,471 & 13.3 \\
\hline Not fastening a seat belt & 6,705 & 8.5 \\
\hline Fastening a seat belt & 1,034 & 1.3 \\
\hline Pedestrian & 2,777 & 3.5 \\
\hline Unknown & 9,812 & 12.4 \\
\hline \multicolumn{3}{|l|}{ Pattern of road traffic crash } \\
\hline Crash with or by motorcycle & 17,075 & 21.7 \\
\hline Crash with or by motor car & 19,119 & 24.2 \\
\hline Crash with or by others & 8,544 & 10.8 \\
\hline Unknown & 34,124 & 43.3 \\
\hline \multicolumn{3}{|l|}{ Mechanism of injuries } \\
\hline Blunt & 69,997 & 88.8 \\
\hline $\begin{array}{l}\text { Penetrating or blunt and } \\
\text { penetrating }\end{array}$ & 7,232 & 9.2 \\
\hline Unknown & 1,633 & 2.0 \\
\hline \multicolumn{3}{|l|}{ Body Region of injuries } \\
\hline Head or neck & 11,388 & 14.4 \\
\hline Facial & 2,808 & 3.6 \\
\hline Chest & 1,308 & 1.7 \\
\hline Abdominal or pelvic cavity & 1,980 & 2.5 \\
\hline Extremities or pelvic girdles & 18,986 & 24.1 \\
\hline External injuries & 36,070 & 45.7 \\
\hline Unknown & 6,322 & 8.0 \\
\hline \multicolumn{3}{|l|}{ The status of injured patients } \\
\hline Died & 1,431 & 1.8 \\
\hline Survived & 77,431 & 98.2 \\
\hline
\end{tabular}


Table 2. The association between factors and road traffic mortality from chi-square test

\begin{tabular}{|c|c|c|c|}
\hline \multirow[t]{2}{*}{ Patient and injury characteristics } & \multicolumn{2}{|c|}{ Road Traffic Injuries } & \multirow[t]{2}{*}{$P$} \\
\hline & $\begin{array}{l}\text { Death } \\
1,431\end{array}$ & $\begin{array}{c}\text { Survival } \\
77,431\end{array}$ & \\
\hline Gender & & & $<0.001$ \\
\hline Female & $354(24.7)$ & $29,817(38.5)$ & \\
\hline Male & $1,077(75.3)$ & $47,614(61.5)$ & \\
\hline Age-group & & & $<0.001$ \\
\hline$<15$ years & $104(7.3)$ & $11,591(15.0)$ & \\
\hline $15-24$ years & $329(23.0)$ & $23,495(30.3)$ & \\
\hline $25-44$ years & $630(44.0)$ & $27,578(35.6)$ & \\
\hline$\geq 45$ years & $368(25.7)$ & $14,767(19.1)$ & \\
\hline Road user and vehicle type in each safety & & & $<0.001$ \\
\hline \multicolumn{4}{|l|}{ device } \\
\hline $\mathrm{D} / \mathrm{P}$ using motorcycle not wearing a helmet & $538(37.6)$ & $46,719(60.3)$ & \\
\hline D/P using motorcycle wearing a helmet & $57(4.0)$ & $10,319(13.3)$ & \\
\hline $\mathrm{D} / \mathrm{P}$ using motor car not fasten seat belt & $142(9.9)$ & $6,338(8.2)$ & \\
\hline D/P using motor car fasten seat belt & $10(0.7)$ & $1,005(1.3)$ & \\
\hline Pedestrians & $100(7.0)$ & $2677(3.5)$ & \\
\hline Others and unknown & $584(40.8)$ & $10,373(13.4)$ & \\
\hline Pattern of road traffic crash & & & $<0.001$ \\
\hline Crash with or by motorcycle & $300(21.0)$ & $16,775(21.7)$ & \\
\hline Crash with or by motor car & $607(42.4)$ & $18,512(23.9)$ & \\
\hline Crash with or by others & $159(11.1)$ & $8,385(10.8)$ & \\
\hline Unknown & $365(25.5)$ & $33,759(43.6)$ & \\
\hline Mechanism of injuries & & & $<0.001$ \\
\hline Blunt & $1,177(82.2)$ & $68,820(88.9)$ & \\
\hline Penetrating or blunt and penetrating & $206(14.4)$ & $7,026(9.1)$ & \\
\hline Unknown & $48(3.4)$ & $1,585(2.0)$ & \\
\hline Body region of injuries & & & $<0.001$ \\
\hline Head or neck & $655(45.8)$ & $10,733(13.9)$ & \\
\hline Facial & $29(2.0)$ & $2,779(3.6)$ & \\
\hline Chest & $51(3.6)$ & $1,257(1.6)$ & \\
\hline Abdominal or pelvic cavity & $69(4.8)$ & $1,911(2.5)$ & \\
\hline Extremities or pelvic girdles & $146(10.2)$ & $18,840(24.3)$ & \\
\hline External injuries & $272(19.0)$ & $35,798(46.2)$ & \\
\hline Unknown & 209 (14.6) & $6,113(7.9)$ & \\
\hline
\end{tabular}

Note: D/P refers to driver or passenger

were crashed by motorcycle by 2.02 times. Having head or neck, chest and abdominal or pelvic cavity injuries induced higher mortality than injuries to extremities or pelvic girdles by $6.96,4.21$, and 4.16 times, respectively, as summarized in Table 3.

\section{Discussion}

This current study assessed the road traffic mortality and its determinants from general hospitals in southern Thailand. Road traffic accident mortality in general hospital records was found to be $1.8 \%$ of all injuries. Gender, age group, road uservehicle type-safety device use, pattern of road traffic crash, mechanism of injuries and body region of injuries were significantly associated with road traffic mortality.

Our study data had fairly low rate of road traffic mortality when compared to other countries, such as $2.2 \%$ from trauma referral in hospitals of Tanzania [25], 4.9\% from trauma center care hospital in Libya [26], and 7.7\% from a teaching hospital in Kenya [6]. This low rate of mortality might be because the severe cases from traffic accidents who were admitted to general hospitals tended to be referred to tertiary hospitals, due to the lack of advanced medical equipment, treatment, and specialists.

In this study, about three-fourths of road traffic mortalities were males. Similar results were found in studies conducted in Ghana by Der et al. [27] and in Vietnam by Ngo et al. [21]. 
Table 3. Factors associated with road traffic mortality from multivariate analysis

\begin{tabular}{|c|c|c|c|}
\hline Variable & $\begin{array}{l}\text { Crude odds ratio } \\
\qquad(95 \% \mathrm{Cl})\end{array}$ & $\begin{array}{l}\text { Adjusted odds ratio } \\
\qquad(95 \% \mathrm{Cl})\end{array}$ & $P$ \\
\hline \multicolumn{4}{|l|}{ Gender } \\
\hline Female & 1 & 1 & \\
\hline Male & $1.90(1.69-2.15)$ & $1.66(1.46-1.88)$ & $<0.001$ \\
\hline \multicolumn{4}{|l|}{ Age-group } \\
\hline$<15$ years & 1 & 1 & \\
\hline $15-24$ years & $1.56(1.25-1.95)$ & $1.95(1.55-2.45)$ & $<0.001$ \\
\hline $25-44$ years & $2.55(2.07-3.14)$ & $2.83(2.28-3.50)$ & $<0.001$ \\
\hline$\geq 45$ years & $2.78(2.23-3.46)$ & $2.82(2.26-3.54)$ & $<0.001$ \\
\hline \multicolumn{4}{|l|}{ Road user and vehicle type in each safety device } \\
\hline $\mathrm{D} / \mathrm{P}$ using motorcycle not wearing a helmet & $2.08(1.59-2.74)$ & $2.08(1.58-2.75)$ & $<0.001$ \\
\hline D/P using motorcycle wearing a helmet & 1 & 1 & \\
\hline $\mathrm{D} / \mathrm{P}$ using motor car not fasten seat belt & $4.06(2.98-5.52)$ & $3.37(2.47-4.61)$ & $<0.001$ \\
\hline $\mathrm{D} / \mathrm{P}$ using motor car fasten seat belt & $1.80(0.92-3.54)$ & $1.34(0.68-2.65)$ & 0.396 \\
\hline Pedestrians & $6.76(4.87-9.39)$ & $5.65(4.03-7.91)$ & $<0.001$ \\
\hline Others and unknown & $10.19(7.76-13.39)$ & $9.44(7.15-12.47)$ & $<0.001$ \\
\hline \multicolumn{4}{|l|}{ Pattern of road traffic crash } \\
\hline Crash with or by motorcycle & 1 & 1 & \\
\hline Crash with or by motor car & $1.83(1.59-2.11)$ & $2.02(1.75-2.34)$ & $<0.001$ \\
\hline Crash with or by others & $1.06(0.87-1.29)$ & $1.05(0.86-1.28)$ & 0.657 \\
\hline Unknown & $0.60(0.52-0.71)$ & $0.60(0.51-0.71)$ & $<0.001$ \\
\hline \multicolumn{4}{|l|}{ Mechanism of injuries } \\
\hline Blunt & 1 & 1 & \\
\hline Penetrating or blunt and penetrating & $1.71(1.48-1.99)$ & $1.55(1.32-1.81)$ & $<0.001$ \\
\hline Unknown & $1.77(1.32-2.37)$ & $1.05(0.77-1.42)$ & 0.768 \\
\hline \multicolumn{4}{|l|}{ Body Region of injuries } \\
\hline Head or neck & $7.87(6.57-9.44)$ & $6.96(5.79-8.63)$ & $<0.001$ \\
\hline Facial & $1.35(0.90-2.01)$ & $1.32(0.88-1.98)$ & 0.173 \\
\hline Chest & $5.24(3.79-7.24)$ & $4.21(3.02-5.86)$ & $<0.001$ \\
\hline Abdominal or pelvic cavity & $4.66(3.49-6.23)$ & $4.16(3.10-5.59)$ & $<0.001$ \\
\hline Extremities or pelvic girdles & 1 & 1 & \\
\hline External injuries & $0.98(0.80-1.20)$ & $1.12(0.91-1.37)$ & 0.289 \\
\hline Unknown & $4.41(3.56-5.46)$ & $3.95(3.18-4.91)$ & $<0.001$ \\
\hline
\end{tabular}

Moreover, this finding is in agreement with the results of several studies $[28,29]$. This might be due to more frequent driving, having driving risk behaviors, and more exposure to driving occupations. The risk of road traffic mortality increased with age. The result matches the findings from several studies [30-34]. This result may be explained by the deterioration in health with aging. Even minor injuries can bring serious health problems, require long time of recovery, and increase the risk of death for elderly persons $[33,34]$.

Pedestrians had elevated risk of mortality. Our finding is consistent with the findings of several prior studies [35-38]. The possible reasons for higher mortality among pedestrians might be more severe impacts, such as pedestrians crashed from back, crashed at high speed or by drink driver, and crashed directly by the vehicle without any protection. Not wearing a helmet or fastening a seat belt gave higher risk of mortality. This finding supports many other studies [1, 4, 7, 39]. Wearing helmet or fastening seat belt can protect against injuries and mortality from accident efficiently. It has been shown that the use of safety helmets and fastening seat belts is a most effective way to reduce mortality and morbidity from traffic injuries [1]. It seems possible that either further education about the benefits of fastening seat belt or helmet use for drivers and passengers or seat belt or helmet laws applied to more drivers or passenger might increase these safe behaviors. In Thailand, helmet was used by more than $25 \%$ of motorcycle drivers between 2005 and 2009 [11], but in this current study only in southern Thailand in 2008-2013 it is shown that the helmet use was less frequent (13.3\%). Government should rigorously enforce laws on using injury-protective devices.

Mortality when crashed with or crashed by motor car was significantly higher than crashed with or crashed by motorcycle. This is supported by studies conducted in Iran, USA, and 
Albania [28, 40-41]. The probability of mortality in the event of a crash with motor car is elevated, but the main road users in this study were motorcycle users. Driving at a high speed is common among car drivers, and this also increases the chances of getting in an accident. Accidents from high-speed driving, drowsiness, fatigue, and driver health status result in severe injuries and mortality $[42,43]$.

Mortality from penetrating or blunt and penetrating was higher than from blunt trauma only. This is because penetrating injuries can be seen from external bleeding, while blunt injuries cannot be evaluated for bleeding from external appearance. The mechanism of blunt and penetrating affects both internal and external organs, thereby tending to have higher severity of injury. Our current study contrasts with other studies that have reported blunt injuries only as the majority in mortality cases, in Iran, USA, and Egypt [13, 44, 45].

Head or neck injuries had higher mortality than injuries to extremities or pelvic girdles. High mortality from head injuries was reported in previous studies, such as in Kenya, Laos, Vietnam, Libya, and China $[6,19,21,26,46]$. This might be due to most drivers and passengers not wearing helmets, despite their use being required by law. In addition, this current study revealed that chest and abdomen or pelvic cavity injuries also had high mortality, because the single vital organ injuries of patients are too serious to be recovered.

There are some limitations to this current study. Some information of patients was not recorded, and there were missing data in almost all the variables. However, the largest percentage of missing data was in the unknown status of fastening seat belt or using helmet. The data used in this study were secondary data and might contain some errors that cannot be detected. Some information related to treatment and the status of patients after discharging from the hospital was not recorded.

\section{Conclusion}

Any policies and measures set up by the authorities to reduce mortality from road traffic injuries should emphasize males, older aged people, pedestrians, not wearing helmet or fastening seat belt, being crashed with or by motor car, having blunt and penetrated as the mechanism of injury, and having head or neck, chest, or abdominal or pelvic cavity injuries.

Author contributions. All the authors contributed substantially to the conception and design of this study and acquisition of data and analyzed and interpreted the data. Sunee Kraonual and Sampurna Kakchapati drafted the manuscript. Apiradee Lim and Attachai Ueranantasun contributed substantially to its critical revision. All the authors approved the final version submitted for publication and take responsibility for the statements made in the published article.

Acknowledgments. The authors are gratefully to those participating in this study. This study was partially funded by the Graduate School, Prince of Songkla University, Thailand, and the Centre of Excellence in Mathematics, the Commission on Higher Education, Thailand. We are grateful to Professor Don McNeil for his helpful advice and suggestions and to Associate Professor Seppo Juhani Karrila for helping improve a manuscript draft. We would like to express our gratitude to the ODPC region for permission to use their data.

Conflict of interest statement. The authors have completed and submitted the International Committee of Medical Journal Editors Uniform Disclosure Form for Potential Conflicts of Interest. None of the authors disclose any conflict of interest.

\section{References}

[1] World Health Organization. Global status report on road safety 2015. Geneva, Switzerland [online]. 2015 [cited 2017 May 1]. Available from: https://www.who.int/violence_injury_prevention/ road_safety_status/2015/GSRRS2015_Summary_EN_final.pdf.

[2] Karkee R, Lee AH. Epidemiology of road traffic injuries in Nepal, 2001-2013: systematic review and secondary data analysis. Br Med J Open. 2016; 6:e010757.

[3] Apidechkul T, Songla T. Traffic injury in Northern Thailand from 2011-2013: a cross sectional survey. Asia Pacific J Public Health. 2016; 7:21-8.

[4] Sango AH, Testa J, Meda N, Contrand B, Traore MS, Staccini P, et al. Mortality and morbidity of urban road traffic crashes in Africa: capture-recapture estimates in Bamako, Mali, 2012. Public Lib Sci. 2016; 12:1-8.

[5] World Health Organization. Road safety in the South-East Asia region 2015, New Delhi, India [online]. 2016 [cited 2017 May 1]. Available from: http://www.who.int/violence_injury_prevention/ road_safety_status/2015/Road_Safety_SEAR_3_for_web.pdf.

[6] Saidi H, Mutiso BK, Ogengo J. Mortality after road traffic crashes in a system with limited trauma data capability. J Trauma Manag Outcomes. 2014; 8:2-6.

[7] Sriwattanapongse W, Prasitwattanaseree S, Khanabsakdi S, Wongtra-ngan S. Mortality rate model due to transportation accidents in Thailand. Silpakorn Univ Sci Technol J. 2013; 7:9-18.

[8] Chalya LP, Mabula JB, Dass RM, Mbelenge N, Ngayomela IH, Chandika $\mathrm{AB}$. Injury characteristics and outcome of road traffic crash victims at Bugando Medical Centre in Northwestern Tanzania. J Trauma Manag Outcomes. 2012; 6:1-8.

[9] Prasannan K, Sheeju PA. Descriptive study of pattern of injuries in driver and pillion rider victims of fatal two wheeler accidents. Asian J Pharm Health Sci. 2015; 5:29-32.

[10] Noosorn N, Wongwat R. Traffic injury correlated to alcohol drinking in the upper Northern region of Thailand. Res J Med Sci. 2010; 2:53-6. 
[11] Chadbunchachai W, Suphanchaimaj W, Settasatien A, Jinwong T. Road traffic injuries in Thailand: current situation. J Med Assoc Thai. 2012; 95(Suppl 7):S274-81.

[12] Naci H, Chisholm D, Baker TD. Distribution of road traffic deaths by road user group: a global comparison. Injury Prev. 2009; 15:55-9.

[13] Ehsaei MR, Sarreshtedar A, Ashraf H, Karimiani EG. Trauma mortality: using Injury Severity Score (ISS) for survival prediction in East of Iran. Razavi Int J Med. 2014; 2:1-4.

[14] Staff T, Eken T, Wik L, Rislien J, Svik S. Physiologic, demographic and mechanistic factors predicting New Injury Severity Score (NISS) in motor vehicle accident victims. Int J Care Injured. 2014; 45(1):9-15.

[15] Ay N, Alp V, Aliosmanoğlu İ, Sevük U, Kaya Ş, Dinç B. Factors affecting morbidity and mortality in traumatic colorectal injuries and reliability and validity of trauma scoring systems. World J Emerg Surg. 2015; 10:21.

[16] Chaudhry N, Naqi SA, Qureshi AU. Effectiveness of TRISS to evaluate trauma care in a developing country. Emerg Med J. 2012; 2:124.

[17] Jha S, Yadav BN, Karn A, Aggrawal A, Gautam A. Epidemiological study of fatal head injury in road traffic accident cases: a study from B P Koirala Institute of Health Sciences, Dharan. Health Renaissance. 2010; 8:97-101.

[18] Farooqui JM, Chavan KD, Bangal RS, Aarif Syed MM, Thacker PJ, Alam S, et al. Pattern of injury in fatal road traffic accidents in a rural area of western Maharashtra, India. Aus Med J. 2013; 9:476-82.

[19] Slesak G, Inthalath S, Wilder-Smith A, Barennes H. Road traffic injuries in northern Laos: trends and risk factors of an underreported public health problem. Trop Med Int Health. 2015; 20:578-87.

[20] Heydari ST, Hoseinzadeh A, Ghaffarpasand F, Hedjazi A, Zarenezhad M, Moafian G. Epidemiological characteristics of fatal traffic accidents in Fars province, Iran: a community-based survey. Public Health. 2013; 127:704-9.

[21] Ngo AD, Rao C, Phuong NP, Hoy DG, Trang KT, Hill PS. Road traffic related mortality in Vietnam: Evidence for policy from a national sample mortality surveillance system. BMC Public Health. 2012; 12:1-9.

[22] World Health Organization Regional Office for South-East Asia. The bi-regional workshop on injury surveillance. New Delhi, India [online]. 2007 [cited 2018 Mar 10]. Available from: http://apps.searo. who.int/PDS_DOCS/B3176.pdf.

[23] Yiengprugsawan V, Berecki-Gisolf J, Bain C, McClure R, Seubsman S, Sleigh AC, et al. Predictors of injury mortality: findings from a large national cohort in Thailand. Br Med J Open. 2014; 1:8.

[24] R Core Team. A language and environment for statistical computing. Vienna, Austria: R Foundation for Statistical Computing; 2016.

[25] Boniface R, Museru L, Kiloloma O, Munthali V. Factors associated with road traffic injuries in Tanzania. Pan Afr Med J. 2016; 23:46.

[26] Emara AM, Greiw AS, Hassan NA. Pattern of road traffic injuries in patients admitted to AI-jlaa hospital, Benghazi, Libya. Tanta Med J. 2015; 43:39-45.

[27] Der EM, Naporo S, Damnyag JB, Akosa AB. Road traffic related deaths in Accra Ghana: A 10 year retrospective autopsy study at the Korle-Bu teaching hospital, Accra (2004-2013). J Forensic Pathol. 2016; 1:1-7.

[28] Hamzeh B, Najafi F, Karaminatin B, Ahmadijiouybari T, Salari A, Moradinazar M. Epidemiology of traffic crash mortality in west of Iran in a 9 year period. Chin J Traumatol. 2016; 19:70-4.
[29] Babalola OR, Oluwadiya K, Vrgoc G, Akpati U, Sindik J, Coklo M, et al. Pattern of emergency room mortality among road traffic crash victims. Int J Care Injured. 2015; 46(Suppl 6):S21-3.

[30] Yu W, Chen H, Lv Y, Deng Q, Kang P, Zhang L. Comparison of influencing factors on outcomes of single and multiple road traffic injuries: A regional study in Shanghai, China (2011-2014). PLoS One. 2017; 5:e0176907.

[31] Hsiao M, Malhotra A, Thakur JS, Sheth J, Nathens AB, Dhingra N, et al. Road traffic injury mortality and its mechanisms in India: nationally representative mortality survey of 1.1 million homes. Br Med J Open. 2013; 3:e002621.

[32] Onieva-García MA, Martínez-Ruiz V, Lardelli-Claret P, JiménezMoleón J, Amezcua-Prieto C, Luna-del-Castillo J, et al. Gender and age differences in components of traffic-related pedestrian death rates: exposure, risk of crash and fatality rate. Injury Epidemiol. 2016; 3(1):14.

[33] Li G, Braver ER, Chen LH. Fragility versus excessive crash involvement as determinants of high death rates per vehicle-mile of travel among older drivers. Accid Anal Prev. 2003; 35:227-35.

[34] Yadollahi M, Ghiassee A, Anver M, Ghaem H, Farahmand M. Analysis of Shahid Rajaee hospital administrative data on injuries resulting from car accidents in Shiraz, Iran: 2011-2014 data. Chin J Traumatol. 2017; 20:27-33.

[35] AI-Thaifani AA, AI-Rabeei NA, Dallak AM. Study of the injured persons and the injury pattern in road traffic accident in Sana'a City, Yemen. Adv Public Health. 2016; 4138163:1-5.

[36] Schlottmann F, Tyson AF, Cairns BA, Varela C, Charles AG. Road traffic collisions in Malawi: Trends and patterns of mortality on scene. Malawi Med J. 2017; 29:301-5.

[37] Sadeghi-Bazargani H, Samadirad B, Moslemi F. A decade of road traffic fatalities among the elderly in North-West Iran. BMC Public Health. 2018; 18:1-7.

[38] Lee JS, Kim YH, Yum JS, Jung SE, Chae CS, Chung MJ. Characteristics of patients injured in road traffic accidents according to the new injury severity score. Ann Rehabil Med. 2016; 40: 288-93.

[39] Zhu M, Cummings P, Chu H, Cook JL. Association of rear seat safety belt use with death in a traffic crash: a matched cohort study. Inj Prev. 2007; 13:183-5.

[40] Paulozzi LJ. United States pedestrian fatality rates by vehicle type. Inj Prev. 2005; 11:232-6.

[41] Qirjako G, Burazeri G, Hysa B, Roshi E. Factors associated with fatal traffic accidents in Tirana, Albania: cross sectional study. Croat Med J. 2008; 49:734-40.

[42] Rosen E, Sander U. Pedestrian fatality risk as a function of car impact speed. Accid Anal Prev. 2009; 41:536-42.

[43] Damsere-Derry J, Ebel BE, Mock CN, Afukaar F, Donkor P. Pedestrians injury patterns in Ghana. Accident analysis and prevention. Accid Anal Prev. 2010; 42:1080-8.

[44] Peng J, Wheeler K, Shi J, Groner JI, Haley K. Trauma with injury score of 75: are these unsurvivable injuries. PLoS One. 2015; 10:e0131362.

[45] Mohamed M, El-Din A, Medhat RN, Mai TM. Blunt versus penetrating chest trauma in terms of the outcome in Menoufia University Hospital. Menoufia Med J. 2018; 31:133-9.

[46] Liu W, Su S, Qiu J, Zhang Y, Yin Z. Exploration of pedestrian head injuries-collision parameter relationships through a combination of retrospective analysis and finite element method. Int J Environ Res Public Health. 2016; 13:1250. 